\title{
Hatching and nutritional quality of Artemia cysts progressively deteriorates as a function of increased exposure to hydration/dehydration cycles
}

\author{
Mohamed Omar El-Magsodi • Peter Bossier • Patrick Sorgeloos • \\ Gilbert Van Stappen
}

Received: 4 April 2013/Accepted: 24 February 2014/Published online: 7 March 2014

(C) Springer International Publishing Switzerland 2014

\begin{abstract}
Nauplii hatching from Artemia cysts are crucial in larviculture nutrition. Artemia cysts may be exposed to repeated hydration/dehydration (H/D) cycles pre-harvesting or during processing and storage. To observe the effect of these cycles on cyst quality, Artemia franciscana cysts were exposed to a comprehensive set of various H/D treatments, differing in the number of cycles $(1,2$, or 3$)$ and the duration of the freshwater hydration period ( 2 or $4 \mathrm{~h}$ ). Cyst quality was assessed using the criteria of immediate relevance for aquaculture use, such as hatching percentage directly after H/D treatment and after $-18{ }^{\circ} \mathrm{C}$ storage up to 1 month, longevity of axenically hatched starved nauplii, cyst and naupliar energy content, and (for the most extreme H/D treatment) cyst and naupliar fatty acid and vitamin $\mathrm{C}$ content. Repeated H/D cycles resulted in significantly $(P<0.05)$ decreased cyst hatching, reduced starved naupliar longevity and individual energy content, loss in vitamin $\mathrm{C}$ and fatty acid content, and moreover a close correlation between these parameters as a function of progressive H/D treatments. This is of immediate relevance for aquaculture nutrition, as commercial Artemia cysts may have gone through an unknown sequence of $\mathrm{H} / \mathrm{D}$ cycles in nature or in the processing line, which affects the nutritional quality of the nauplii used in larviculture operations.
\end{abstract}

Keywords Artemia - Hydration/dehydration cycles · Energy content · Quality control · Live food · Fatty acid

M. O. El-Magsodi $(\bowtie) \cdot$ P. Bossier · P. Sorgeloos · G. Van Stappen Laboratory of Aquaculture and Artemia Reference Center, Faculty of Bioscience Engineering, Ghent University, Rozier 44, 9000 Ghent, Belgium e-mail:magsodi@yahoo.co.uk

M. O. El-Magsodi

Department of Aquaculture, Faculty of Agriculture, Tripoli University, Tripoli, Libya 


\section{Introduction}

The brine shrimp Artemia (Crustacea, Anostraca) is the main zooplanktonic organism that inhabits hypersaline environments all over the world (Triantaphyllidis et al. 1998). This branchiopod has acquired extremely capable adaptive mechanisms to survive and evolve in habitats with extensive and often abrupt fluctuations in abiotic conditions such as salinity, UV irradiation, temperature, and oxygen concentration (Persoone and Sorgeloos 1980). These mechanisms are poorly understood, although several studies have shown the ways that Artemia responds to varying abiotic conditions prevailing in its natural habitats (for review, see Abatzopoulos et al. 2002 and references therein). To survive environmental stress, Artemia has developed two different reproductive patterns, with females releasing either swimming larvae (nauplii) or encysted gastrulae (cysts) (MacRae 2003). When cysts are produced, the embryo enters diapause, a reversible physiological condition during which metabolism is greatly reduced and stress tolerance is increased (Drinkwater and Clegg 1991; Clegg 1997; MacRae 2003, 2005). Exposure to habitat-specific environmental stimuli, such as desiccation and/or low temperature, promotes resumption of cyst development and metabolism (Drinkwater and Crowe 1987; Van Der Linden et al. 1988; Drinkwater and Clegg 1991; Nambu et al. 2008).

The first use of Artemia nauplii, hatched from cysts, is known from the 1930s when this zooplankton organism was used as a suitable food source for fish larvae in the culture of commercially important species (Sorgeloos 1980; Léger et al. 1986). Since then, Artemia has been found to be a suitable food for diverse groups of organisms of the animal kingdom, especially for a wide variety of marine and freshwater crustaceans and fishes (Sorgeloos 1980).

Cyst hatching is determined by a variety of factors, including genetic factors, the degree of diapause termination, ambient conditions before and during harvesting, processing and storage procedures, and ambient conditions during the hatching incubation process itself. One of the most effective methods for deactivating diapause in cysts of the San Francisco Bay (SFB)-type Artemia franciscana (Kellogg 1906) in laboratory conditions is dehydration or well-controlled consecutive hydration/dehydration (H/D) cycles (Sorgeloos et al. 1976; Vanhaecke and Sorgeloos 1982; Lavens et al. 1986). Quiescent cysts (out of diapause) on the other hand may go through H/D cycles when being exposed to ambient conditions preharvest in natural habitats or during processing procedures. This may result in variable quality loss exemplified by reduced and/or delayed hatching especially after storage (Vanhaecke and Sorgeloos 1982; Lavens and Sorgeloos 1987). Though some H/D exposure is, to a certain extent, an almost unavoidable element in the history of any commercial cyst sample from pre-harvesting until marketing, and though the related decline in hatching can be substantial, no systematical research has been done in this respect.

This study assumed that the loss of hatching quality as a consequence of one or more $\mathrm{H} / \mathrm{D}$ cycles would be proportional to the magnitude of the exposure and the duration of subsequent storage. It further assumed that this treatment would also result in deterioration of other quality characteristics relevant for the use of brine shrimp as live food in larviculture. For this purpose, cysts of two A. franciscana strains (Great Salt Lake, USA, and the San Francisco Bay-type Vinh Chau, Vietnam) that are of prime importance for global cyst supply were subjected to different treatments each including one or more H/D steps in well-defined experimental conditions. The quality of the resulting embryos was assessed using practical criteria relevant for their use in aquaculture: hatching quality, longevity of starved nauplii and nutritional quality measured as energy content, HUFA, and vitamin C levels of cysts and nauplii. 


\section{Materials and methods}

\section{Cyst samples}

Experiments were performed with two strains of A. franciscana: one commercial dry sample (water content $4.5 \pm 0.2 \%$ ) originating from Great Salt Lake (GSL), Utah, USA (INVE Aquaculture Belgium, Type EG (batch number: 21425), and a second sample from Vinh Chau (VC) salt fields, Vietnam (ARC code 1718), supplied by Can Tho University, Vietnam, being dehydrated and stored in saturated $\mathrm{NaCl}$ brine (water content $34.8 \pm 1.8 \%$ ). Both samples had been stored at $+4{ }^{\circ} \mathrm{C}$ since their arrival at the Laboratory of Aquaculture \& Artemia Reference Center. Water content of cysts was determined by drying a subsample of raw cysts in an oven for $4 \mathrm{~h}$ at $103{ }^{\circ} \mathrm{C}$ to a constant weight.

\section{Hydration/dehydration cycles}

Cysts were exposed to successive hydration/dehydration (H/D) cycles by incubating $1.6 \mathrm{~g}$ of cysts of each strain in a 1-1 cylindroconical glass cone containing $800 \mathrm{ml}$ of medium (freshwater for the hydration step and $\mathrm{NaCl}$-saturated brine $\left(280-300 \mathrm{~g} \mathrm{l}^{-1}\right.$ ) for the dehydration step) at $28{ }^{\circ} \mathrm{C}$ under strong aeration. A first group of three cones was set up; the cysts in the first cone were exposed to one H/D cycle (2-h hydration and 24-h dehydration), the second one to two cycles, and the third one to three (named A1, A11, and A111, respectively). In parallel, for each strain, three other cones went through a similar setup, but with each hydration period lasting for $4 \mathrm{~h}$ (the corresponding treatments named $\mathrm{A} 2$, A22, and A222). After the H/D steps, the cyst samples were immediately stored in $+4{ }^{\circ} \mathrm{C}$ in NaCl-saturated brine $\left(280-300 \mathrm{~g} \mathrm{l}^{-1}\right)$ until use for any of the tests described under 2.4, 2.5, 2.6, and 2.7.

\section{Determination of hatching percentage $(\mathrm{H} \%)$}

For the determination of $\mathrm{H} \%$ of hydrated/dehydrated cysts, the above procedure was performed in triplicate for each treatment; determination of the hatching percentage was accordingly performed in triplicate. Each sample having gone through the H/D cycles (and a control, not exposed to H/D) was incubated in $800 \mathrm{ml}$ Instant Ocean ${ }^{\circledR}$ solution of $32 \pm 1 \mathrm{~g} \mathrm{l}^{-1}$ in 1-1 cylindroconical glass cones under continuous illumination (2000 lux) at $28.0 \pm 0.5{ }^{\circ} \mathrm{C}$ (Lavens and Sorgeloos 1996). Aeration was provided from the bottom to keep all the cysts in suspension.

After $24 \mathrm{~h}$ of incubation, six subsamples of $250 \mu \mathrm{l}$ each were taken from each cone with a micropipette and placed in a small vial. Nauplii were fixed by adding a few drops of lugol solution and tap water. The nauplii as well as the umbrellae were counted under the microscope. The unhatched cysts were subsequently decapsulated by adding a few drops of $\mathrm{NaOCl}$ and $\mathrm{NaOH}$ solution to each vial (Bruggeman et al. 1980), and the orange-colored embryos were counted, according to the procedure described by (Lavens and Sorgeloos 1996). The hatching percentage was calculated as follows:

$$
H \%=N /(N+U+E) \times 100
$$

where $N=$ number of nauplii, $U=$ number of umbrellae, $E=$ number of embryos.

The mean hatching value per cone was recorded, and the overall mean hatching percentage and standard deviation for the three replicate cones were calculated. $\mathrm{H} \%$ was 
determined at day 0 (= immediately after the H/D treatment), after 1 week, and 1 month of storage at $-18{ }^{\circ} \mathrm{C}$. The stored samples were placed at room temperature $\left( \pm 22{ }^{\circ} \mathrm{C}\right)$ for one day before $\mathrm{H} \%$ testing.

The hatching rate was only determined for non-treated cysts (control), by the determination of the hatching percentage obtained after a hatching incubation period of 10,12 , $14,16,18,20,22,24$, and $48 \mathrm{~h}$.

\section{Axenic Artemia culture}

Axenic Artemia nauplii of each strain were obtained following decapsulation of samples of hydrated/dehydrated cysts (obtained according to the procedure described above) and subsequent hatching procedures described by Marques et al. (2004). A few grams of hydrated/dehydrated cysts were hydrated in $90 \mathrm{ml}$ tap water for $1 \mathrm{~h}$ with strong aeration in non-axenic conditions. The recipient with the cysts was then transferred to a laminar flow hood, where decapsulation was performed using autoclaved and sterile tools. Aeration of the Artemia cysts was pumped through a $0.22-\mu \mathrm{m}$ filter. Then, $50 \mathrm{ml}$ of cold $\mathrm{NaOCl}$ containing $15 \%$ (w/v) active chlorine and $3.3 \mathrm{ml}$ of $32 \%(\mathrm{w} / \mathrm{v}) \mathrm{NaOH}$ was added to the hydrated cysts. The reaction was stopped after $150 \mathrm{~s}$ by adding $70 \mathrm{ml}$ of sterile $\mathrm{Na}_{2} \mathrm{~S}_{2} \mathrm{O}_{3} \cdot 5 \mathrm{H}_{2} \mathrm{O}\left(10 \mathrm{mg} \mathrm{l}^{-1}\right)$. Decapsulated cysts were washed several times carefully with filtered autoclaved seawater (FASW) and collected over a 50- $\mu \mathrm{m}$ sterile sieve. A few mg of these cysts were then transferred to separate, sterile 50-ml falcon tubes (four replicates per $\mathrm{H} / \mathrm{D}$ treatment) containing $30 \mathrm{ml}$ of FASW and capped. For hatching incubation, the tubes were placed on a rotor at 4 cycles/min to prevent clogging and sedimentation of the cysts. Cysts were kept at $28.0 \pm 0.5^{\circ} \mathrm{C}$ and exposed to constant incandescent light (2,000 lux). After 18-20 h, 20 hatched nauplii were picked and transferred to new sterile 50-ml falcon tubes containing $30 \mathrm{ml}$ of FASW, which were mounted on the rotor and incubation was continued. After 12, 24, 36, and $48 \mathrm{~h}$, during which the larvae were not fed, swimming larvae were counted and survival percentage was calculated, as described by Baruah et al. (2010).

Axenity of decapsulated cysts and Artemia culture at the end of each experiment was checked by plating $100 \mu \mathrm{l}$ of the culture medium on marine agar 2216 in two replicates (Difco, Detroit, USA) and incubation for five days at $28.0^{\circ} \mathrm{C}$. In case of contamination, cultures were discarded and the treatment was repeated.

Energy content determination

A subsample of a few $\mathrm{g}$ of decapsulated cysts of each H/D treatment was washed carefully with sterile distilled water over a sterile net (50- $\mu \mathrm{m}$ pores); a few hundred $\mathrm{mg}$ of these cysts was then oven-dried at $60.0^{\circ} \mathrm{C}$ for $24 \mathrm{~h}$. The remaining cysts were transferred to sterile $500-\mathrm{ml}$ hatching bottles containing $400 \mathrm{ml}$ of FASW. The bottles were incubated at $28.0 \pm 0.5^{\circ} \mathrm{C}$ and constantly exposed to light. After $24 \mathrm{~h}$, hatched larvae were harvested and oven-dried at $60.0^{\circ} \mathrm{C}$ for $24 \mathrm{~h}$. Energy content of decapsulated cysts and nauplii was analyzed on one replicate sample of approximately $0.5 \mathrm{~g}$ dry material per treatment group using a bomb calorimeter (C-7000, Ika, Heitersheim, Germany) at the Particle and Interfacial Technology Group, Faculty of Bioscience Engineering, Ghent University, Belgium. In order to calculate the individual cyst energy content, the number of cysts per gram dry weight was determined by counting the cysts under the microscope for three replicate samples of $1 \mathrm{mg}$. 
Fatty acid analysis

To reduce analytical costs, for each strain, only the raw sample and the A222 treatment (which corresponded with the most extreme H/D treatment) were subjected to fatty acid analysis of decapsulated cysts and instar I nauplii (analysis run in one replicate). Fatty acid composition was determined by gas chromatography according to a modified procedure of Lepage and Roy (1984). This method involves direct acid catalyzed transesterification of dry samples of 10-150 mg without prior extraction of total fat. Ten percent of an internal standard 20:2(n-6) was added before the reaction. Fatty acid methyl esters (FAME) were extracted with hexane. After evaporation of the solvent, the FAME was prepared for injection by redissolving it in isooctane $\left(2 \mathrm{mg} \mathrm{ml}^{-1}\right)$. Quantitative determination was done by a Chrompack CP9001 gas chromatograph equipped with an autosampler and a temperature programmable on-column injector. Identification was based on standard reference mixtures (Nu-Chek-Prep, Inc., USA). Integration and calculations were done using the software program Maestro (Chrompack).

\section{Vitamin $\mathrm{C}$ analysis}

Vitamin $\mathrm{C}$ analysis was performed on the same limited set of samples as used for fatty acid analysis. Vitamin $\mathrm{C}$ was determined by a paired-ion, reversed-phase, high-performance liquid chromatography (HPLC) procedure coupled with electrochemical detection and internal standard quantisation based on isoascorbic acid (IAA). The HPLC apparatus consisted of a Varian 8500 pump (Varian Assoc., Palo Alto, CA, USA), an N60 valve injector fitted with a 20- $\mu$ l loop (Valco, Houston, TX, USA), and a Coulochem 5100A electrochemical detector (ESA, Inc., Bedford, MA, USA) equipped with a model 5010 or 5011 analytical cell.

\section{Statistical analysis}

Hatching and survival percentages data were Arcsin-transformed, and normal distribution and homocedasticity requirements were tested (using Levene's test) before further statistical analysis. For each strain and different duration of storage, the data of hatching percentage for $24 \mathrm{~h}$ were subjected to one-way ANOVA to detect an effect of the hydration/dehydration treatments. Similarly, for each strain and hydration/dehydration treatment, the data of hatching percentage for $24 \mathrm{~h}$ were subjected to one-way ANOVA to detect an effect of the storage period. Additionally, for each strain, survival data after 12, 24,36 , and $48 \mathrm{~h}$ of starvation of metanauplii were each subjected to a one-way ANOVA to detect an effect of the hydration/dehydration treatments. Finally, for each strain, also the values for the number of cysts per gram were subjected to a one-way ANOVA to detect an effect of the hydration/dehydration treatments. For all one-way ANOVA's, $P<0.05$ was considered as significant. A two-factor ANOVA test (SPSS, version 12.0) was used to detect significant interactions between the duration of the hydration period ( 2 or $4 \mathrm{~h}$ ) and the number of $\mathrm{H} / \mathrm{D}$ cycles $(1,2$, and 3 cycles) for hatching and survival percentages, and $P<0.05$ was considered as significant. Tukey's test was used to detect significant differences between the experimental sample means, and $P<0.05$ was considered as significant. Linear regression was used to determine the relationship between parameters in the H/D experiment and $P<0.05$ was considered as significant. For this analysis, hatching percentages after different period of storage were linearly regressed against the energy content of the cysts exposed to various H/D cycles using a scatterplot in Microsoft Excel. 
Similarly, survival percentages after different periods of starvation of metanauplii were linearly regressed against the energy content of instar I nauplii after exposure of cysts to various H/D cycles. Per strain and storage period, pooled standard error of means (PSEM) of hatching percentage was calculated using the formula PSEM $=\sqrt{ } \mathrm{MSE} / n$ (whereby MSE is mean square of groups, and $n$ is number of observations), pooling the values obtained after different H/D cycles. Similarly, for each strain, PSEM was calculated for the survival percentages found after a starvation period of $12,24,36$, and $48 \mathrm{~h}$.

\section{Results}

Hatching characteristics

The hatching percentage of the raw material was $90.1 \pm 0.3 \%$ for GSL and $95.1 \pm 1.2 \%$ for VC. From the hatching curve (Fig. 1), $T_{0}$ (time of first cyst hatching) and $T_{10}$ (time of $10 \%$ hatching), derived graphically, were 10 and $11 \mathrm{~h}$ for GSL and 10 and $10.5 \mathrm{~h}$ for VC, respectively. The cysts showed $90 \%$ of their maximum hatchability $\left(T_{90}\right)$ at $24 \mathrm{~h}$ for GSL and $20 \mathrm{~h}$ for $\mathrm{VC}$. The hatching synchrony $\left(T_{S}=T_{90}-T_{10}\right)$ was different between the strains (13 h for GSL and $9.5 \mathrm{~h}$ for VC) (Fig. 1).

Successive hydration/dehydration cycles increasingly affected the hatching percentage. For GSL cysts of the A1 group, $\mathrm{H} \%$ was $84.8 \%$ on day zero, $80.6 \%$ after 1 week, and $79.6 \%$ after 1 month of storage. $\mathrm{H} \%$ values for the equivalent $\mathrm{VC}$ samples were very similar (Table 1). For each strain, $\mathrm{H} \%$ of the untreated cysts was significantly higher than that of H/D cysts regardless of the number and duration of H/D cycles and the duration of storage, except for A1/day 0 GSL cysts and A1/1 month VC cysts, where the difference with the untreated cysts was not significant. For GSL cysts, hatchability significantly decreased (Table 1; Fig. 2a) with increasing hydration time and H/D cycles; this decrease was much more prominent for the samples of the A2 series than for the A1 samples, finally resulting for the A222 group in hatching percentages of $42.7 \%$ on day zero, $41.6 \%$ after 1 week, and $36.4 \%$ after 1 month of storage. Interaction between the duration of hydration and the number of H/D cycles was significant, when analyzing the hatching percentage values before storage, after 1 week, and 1 month of storage $(P<0.05)$. The results for the VC cysts showed a similar trend (Table 1; Fig. 2b). Storage always resulted in loss of hatching, though the decrease was generally not significant (Table 1).

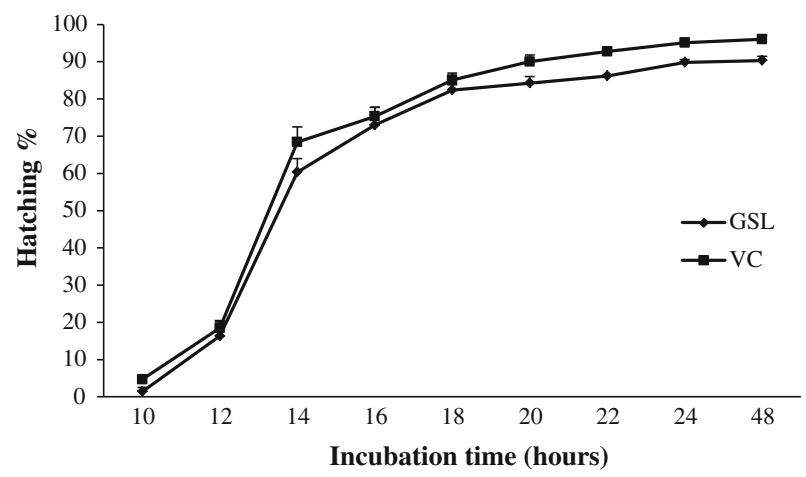

Fig. 1 Hatching curves of untreated cysts from Great Salt Lake (GSL) and Vinh Chau (VC). Mean values and standard deviation (error bars) of three replicates 
Table 1 Hatching percentage (after 24-h hatching incubation) of cysts from GSL and VC strains previously exposed to different duration of the hydration period ( 2 or $4 \mathrm{~h})$ and different number of H/D cycles (1, 2, and 3 cycles)

\begin{tabular}{|c|c|c|c|c|}
\hline \multirow[t]{2}{*}{ Strain } & \multirow[t]{2}{*}{ Treatment } & \multicolumn{3}{|c|}{ Hatching percentage after storage at $-18{ }^{\circ} \mathrm{C}$ for different durations } \\
\hline & & Day 0 (prior to storage) & 1 week & 1 month \\
\hline \multirow[t]{9}{*}{ GSL } & Control & $90.1 \pm 0.3^{\mathrm{aA}}$ & $89.1 \pm 1.1^{\mathrm{aA}}$ & $87.7 \pm 2.2^{\mathrm{aA}}$ \\
\hline & A1 & $84.8 \pm 0.2^{\mathrm{abA}}$ & $80.6 \pm 1.8^{\mathrm{bB}}$ & $79.6 \pm 2.5^{\mathrm{bB}}$ \\
\hline & A11 & $79.1 \pm 2.6^{\mathrm{bA}}$ & $78.9 \pm 3.3^{\mathrm{bA}}$ & $78.7 \pm 0.8^{\mathrm{bA}}$ \\
\hline & A111 & $77.3 \pm 2.5^{\mathrm{bA}}$ & $76.0 \pm 1.7^{\mathrm{bA}}$ & $75.5 \pm 1.4^{\mathrm{bA}}$ \\
\hline & $\mathrm{A} 2$ & $66.7 \pm 2.5^{\mathrm{cA}}$ & $64.0 \pm 1.2^{\mathrm{cA}}$ & $61.9 \pm 2.2^{\mathrm{cA}}$ \\
\hline & A22 & $55.8 \pm 1.3^{\mathrm{dA}}$ & $54.1 \pm 1.4^{\mathrm{dA}}$ & $52.9 \pm 2.3^{\mathrm{dA}}$ \\
\hline & A 222 & $42.7 \pm 5.9^{\mathrm{eA}}$ & $41.6 \pm 3.8^{\mathrm{eA}}$ & $36.4 \pm 5.7^{\mathrm{eA}}$ \\
\hline & Pooled SEM* & \pm 1.6 & \pm 1.3 & \pm 1.6 \\
\hline & Interaction $* *$ & $P=0.010$ & $P=0.001$ & $P=0.000$ \\
\hline \multirow[t]{9}{*}{$\mathrm{VC}$} & Control & $95.1 \pm 1.2^{\mathrm{aA}}$ & $92.7 \pm 0.8^{\mathrm{aAB}}$ & $91.2 \pm 1.1^{\mathrm{aB}}$ \\
\hline & A1 & $88.9 \pm 0.2^{\mathrm{bA}}$ & $87.6 \pm 1.7^{\mathrm{bA}}$ & $87.5 \pm 1.7^{\mathrm{abA}}$ \\
\hline & A11 & $85.0 \pm 1.9^{\mathrm{cA}}$ & $83.9 \pm 1.4^{\mathrm{cA}}$ & $83.2 \pm 1.0^{\mathrm{bcA}}$ \\
\hline & A111 & $83.8 \pm 0.8^{\mathrm{cA}}$ & $82.3 \pm 0.9^{\mathrm{cAB}}$ & $80.9 \pm 1.1^{\mathrm{cB}}$ \\
\hline & $\mathrm{A} 2$ & $64.2 \pm 1.2^{\mathrm{dA}}$ & $61.8 \pm 1.7^{\mathrm{dAB}}$ & $60.0 \pm 1.3^{\mathrm{dB}}$ \\
\hline & A22 & $52.8 \pm 0.8^{\mathrm{eA}}$ & $50.8 \pm 1.2^{\mathrm{eA}}$ & $50.6 \pm 1.1^{\mathrm{eA}}$ \\
\hline & A222 & $42.9 \pm 0.8^{\mathrm{fA}}$ & $40.9 \pm 0.1^{\mathrm{fA}}$ & $35.7 \pm 3.1^{\mathrm{fB}}$ \\
\hline & Pooled SEM* & \pm 0.6 & \pm 0.7 & \pm 0.9 \\
\hline & Interaction $* *$ & $P=0.000$ & $P=0.000$ & $P=0.000$ \\
\hline
\end{tabular}

For each strain and different duration of storage, small superscripts in each column show significant difference between different hydration/dehydration treatments (one-way ANOVA). For each strain and each hydration/dehydration treatment, capital superscripts in each row show significant differences between different duration of storage (one-way ANOVA). ** Interaction between duration of hydration $(2$ or $4 \mathrm{~h})$ and number of H/D cycles (1, 2, or 3 cycles) (two-way ANOVA). Data are mean value $(n=3) \pm$ standard deviation and * pooled standard error of means (pooled SEM). Significance level was set at $\mathrm{P}<0.05$

GSL Great Salt Lake, VC Vinh Chau. A1 = 2-h hydration $+24-\mathrm{h}$ dehydration (1 cycle). A2 = 4-h hydration $+24-\mathrm{h}$ dehydration $(1$ cycle $)$, A11 $=2$-h hydration $+24-\mathrm{h}$ dehydration $(2$ cycles $)$. A22 $=4-\mathrm{h}$ hydration $+24-\mathrm{h}$ dehydration $(2$ cycles $)$, A111 $=2$-h hydration $+24-\mathrm{h}$ dehydration ( 3 cycles). A222 = 4-h hydration $+24-\mathrm{h}$ dehydration $(3$ cycles)

\section{Survival of starved nauplii under axenic conditions}

At the first observation (12-h post-hatching), nauplii of the control group (both for GSL and VC) showed the highest survival (78.8 and 86.3\%, respectively) (Table 2); in the treatment groups, survival was inversely proportional to the number of $\mathrm{H} / \mathrm{D}$ cycles and especially to the duration of the hydration period $(2$ vs. $4 \mathrm{~h}$ ). Interaction between the duration of the hydration period ( $2 \mathrm{~h}$ and $4 \mathrm{~h}$ ) and the number of H/D cycles was only significant $(P<0.05)$ for the survival at $12 \mathrm{~h}$ of the GSL strain. All groups of nauplii showed increasing mortality throughout the 48-h observation period. This resulted in a significantly lower $(P<0.05)$ GSL and VC survival for all A2 treatments as compared to the control for any moment of observation. Also, for the A1 treatments, the divergence from the control value grew as the number of $\mathrm{H} / \mathrm{D}$ cycles increased. Overall, the 

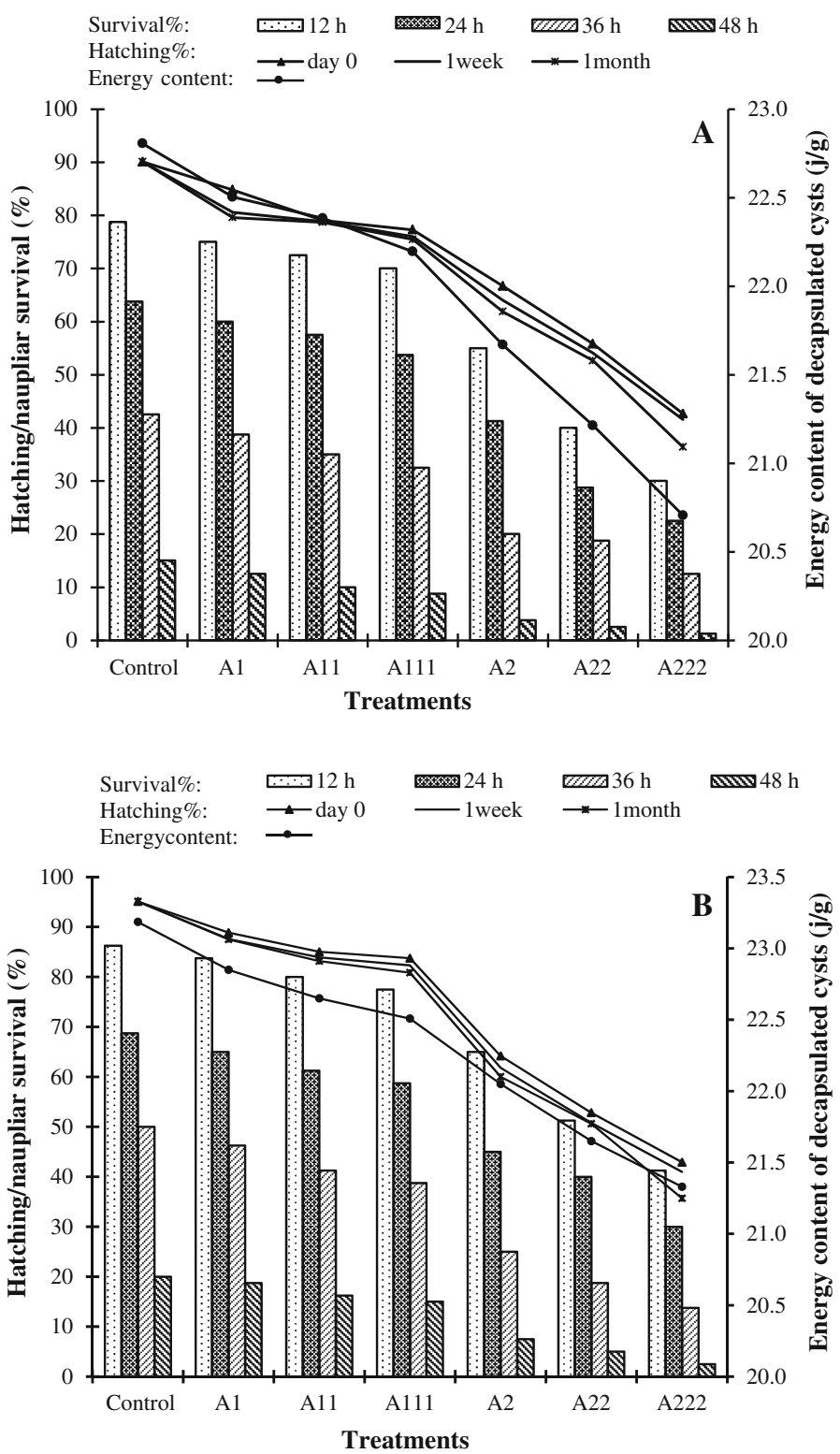

Fig. 2 a Hatching percentage (on day 0, after 1 week, and 1 month storage, respectively), energy content (line graphs), and percentage survival of the corresponding starved newly hatched nauplii (at 12, 24, 36, and $48 \mathrm{~h}$, respectively, bar graph) of decapsulated GSL cysts previously exposed to various H/D cycles. For abbreviations, see Table 1. b Hatching percentage (on day 0, after 1 week, and 1 month storage, respectively), energy content (line graphs) and percentage survival of the corresponding starved newly hatched nauplii (at 12, 24, 36, and $48 \mathrm{~h}$, respectively, bar graph) of decapsulated VC cysts previously exposed to various H/D cycles. For abbreviations, see Table 1 


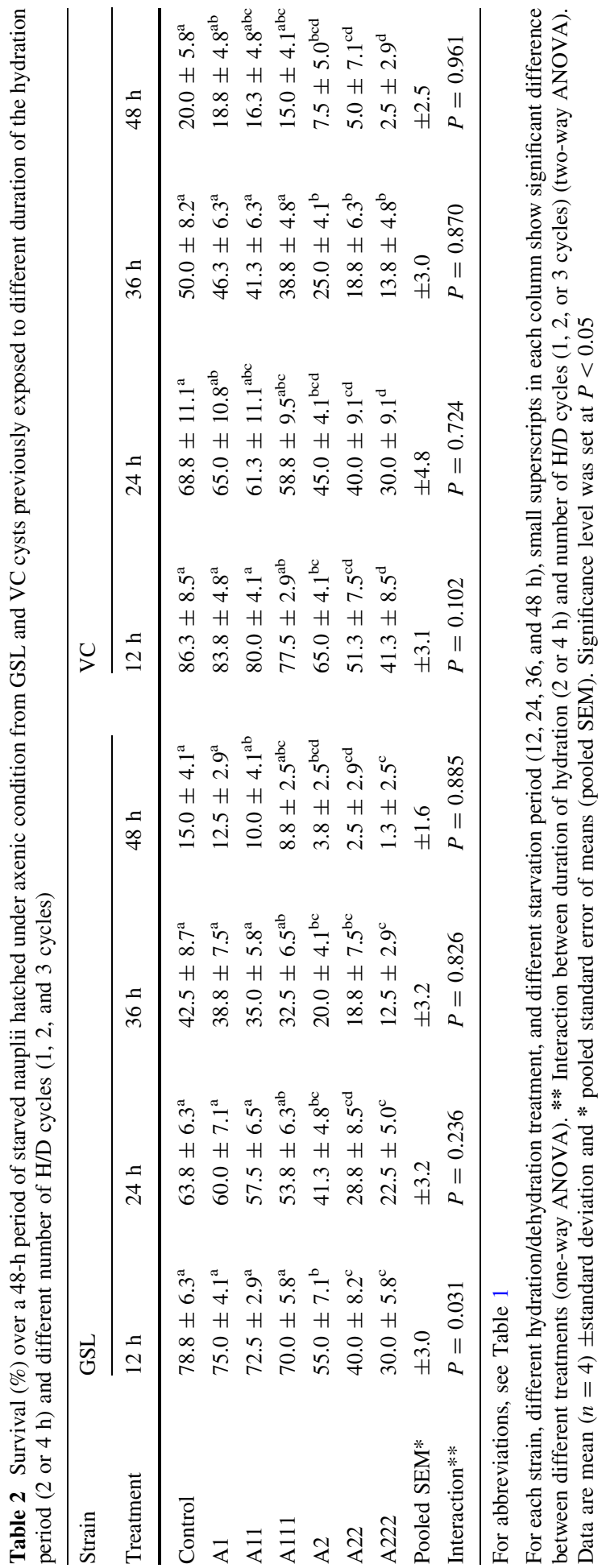




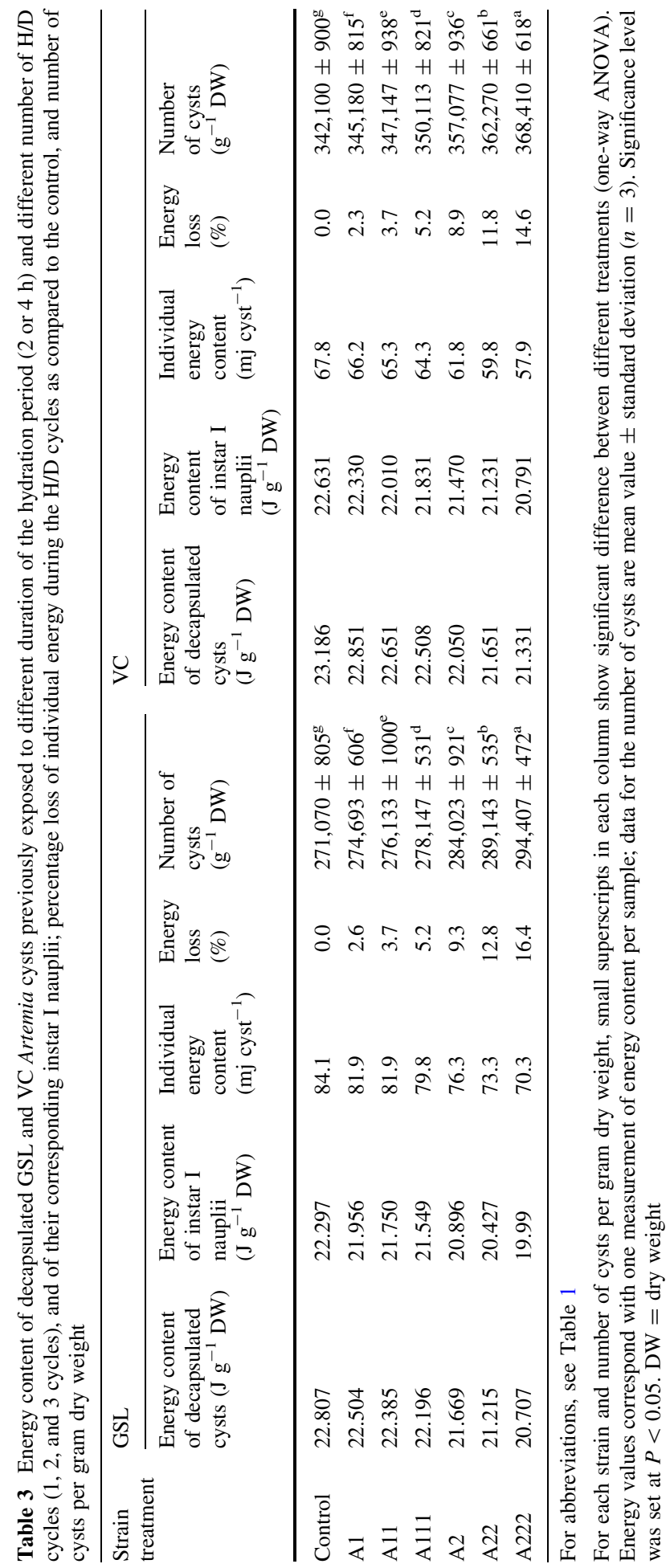


Table 4 Fatty acid methyl esters (FAME) composition $\left(\mathrm{mg} \mathrm{g}^{-1} \mathrm{DW}\right)$ and vitamin C contents $\left(\mathrm{mg} \mathrm{g}^{-1} \mathrm{DW}\right)$ in control and A222 decapsulated cysts and in the corresponding instar I nauplii of GSL and VC Artemia

\begin{tabular}{|c|c|c|c|c|c|c|c|c|}
\hline \multirow{3}{*}{$\begin{array}{l}\text { Strain } \\
\text { FAME }\end{array}$} & \multicolumn{4}{|l|}{ GSL } & \multicolumn{4}{|l|}{$\mathrm{VC}$} \\
\hline & \multicolumn{2}{|l|}{ Cysts } & \multicolumn{2}{|l|}{ Nauplii } & \multicolumn{2}{|l|}{ Cysts } & \multicolumn{2}{|l|}{ Nauplii } \\
\hline & Control & A222 & Control & A222 & Control & A222 & Control & A 222 \\
\hline $14: 00$ & 1.3 & 1.1 & 0.9 & 0.9 & 3.3 & 3.0 & 3.0 & 2.9 \\
\hline $14: 1 n-5$ & 1.7 & 1.6 & 1.7 & 1.6 & 1.1 & 1.0 & 1.1 & 1.1 \\
\hline $15: 00$ & 0.3 & 0.3 & 0.2 & 0.2 & 6.1 & 5.7 & 5.6 & 5.6 \\
\hline $15: 1 n-5$ & 0.7 & 0.3 & 0.8 & 0.3 & 0.6 & 0.6 & 0.6 & 0.6 \\
\hline $16: 00$ & 17.0 & 16.5 & 16.2 & 15.7 & 19.4 & 18.0 & 18.9 & 18.3 \\
\hline $16: 1 n-7$ & 3.8 & 3.7 & 3.2 & 3.0 & 17.0 & 15.8 & 17.0 & 16.9 \\
\hline $17: 00$ & 1.1 & 1.0 & 1.1 & 1.0 & 6.7 & 4.8 & 7.0 & 5.4 \\
\hline $17: 1 n-7$ & 1.4 & 1.3 & 1.3 & 1.2 & 2.1 & 1.7 & 2.0 & 1.9 \\
\hline $18: 00$ & 7.1 & 6.7 & 5.6 & 7.8 & 4.8 & 4.4 & 5.4 & 5.1 \\
\hline $18: 1 n-9$ & 27.5 & 25.8 & 27.3 & 26.2 & 20.9 & 19.2 & 22.8 & 20.7 \\
\hline $18: 1 n-7$ & 8.5 & 8.2 & 8.8 & 8.7 & 14.5 & 13.3 & 15.1 & 15.6 \\
\hline $18: 2 n-6^{t}$ & 0.4 & 0.4 & 0.4 & 0.4 & 0.3 & 0.1 & 0.4 & 0.4 \\
\hline $18: 2 n-6^{s}$ & 9.2 & 9.0 & 10.0 & 9.9 & 4.4 & 4.1 & 4.8 & 4.7 \\
\hline $19: 00$ & 0.1 & 0.1 & 0.1 & 0.1 & 0.0 & 0.0 & 0.0 & 1.5 \\
\hline $18: 3 n-6$ & 1.3 & 1.3 & 1.4 & 1.4 & 1.3 & 1.3 & 1.3 & 1.3 \\
\hline $19: 1 n-9$ & 0.5 & 0.4 & 0.5 & 0.5 & 1.3 & 1.2 & 1.5 & 1.5 \\
\hline $18: 3 n-3$ & 43.6 & 43.4 & 51.4 & 51.8 & 3.8 & 3.6 & 4.4 & 4.3 \\
\hline $18: 4 n-3$ & 9.8 & 9.8 & 11.5 & 11.7 & 1.6 & 1.4 & 1.5 & 1.4 \\
\hline 20:00 & 0.1 & 0.1 & 0.2 & 0.2 & 0.4 & 0.1 & 0.3 & 0.1 \\
\hline $20: 1 n-9$ & 0.7 & 0.6 & 1.0 & 0.9 & 1.4 & 1.2 & 0.8 & 1.2 \\
\hline $20: 1 n-7$ & 0.1 & 0.1 & 0.2 & 0.1 & 0.2 & 0.2 & 1.9 & 0.2 \\
\hline $20: 3 n-6$ & 0.2 & 0.1 & 0.2 & 0.2 & 0.5 & 0.4 & 0.5 & 0.5 \\
\hline $20: 4 n-6$ & 0.4 & 0.4 & 0.3 & 0.3 & 6.0 & 5.6 & 6.7 & 6.5 \\
\hline $20: 3 n-3$ & 1.5 & 1.4 & 2.2 & 2.2 & 0.1 & 0.1 & 0.2 & 0.1 \\
\hline $20: 4 n-3$ & 1.6 & 1.6 & 2.2 & 2.2 & 0.7 & 0.6 & 0.6 & 0.9 \\
\hline $22: 00$ & 0.3 & 0.3 & 0.6 & 0.5 & 0.3 & 0.1 & 0.4 & 0.4 \\
\hline $20: 5 n-3$ & 1.6 & 1.6 & 1.2 & 1.2 & 17.6 & 17.0 & 19.9 & 19.6 \\
\hline $22: 6 n-3$ & 0.0 & 0.0 & 0.1 & 0.0 & 0.2 & 0.0 & 0.2 & 0.0 \\
\hline Total (n-3) & 4.9 & 4.8 & 6.1 & 5.8 & 19.0 & 18.0 & 21.6 & 21.0 \\
\hline Total (n-6) & 11.5 & 11.2 & 12.3 & 12.2 & 12.7 & 11.6 & 13.9 & 13.5 \\
\hline Total (SFA) & 27.3 & 26.1 & 24.9 & 26.4 & 41 & 36.1 & 40.6 & 39.3 \\
\hline Total MUFA & 44.9 & 42.0 & 44.8 & 42.5 & 59.1 & 54.2 & 62.8 & 59.7 \\
\hline Total PUFA & 69.6 & 69.0 & 80.9 & 81.3 & 36.5 & 34.2 & 40.5 & 39.7 \\
\hline Total FAME & 153.3 & 149.3 & 165.8 & 162.9 & 171.9 & 166.5 & 182.1 & 173.7 \\
\hline Vitamin C & 0.367 & 0.112 & 0.803 & 0.724 & 0.289 & 0.111 & 0.676 & 0.611 \\
\hline
\end{tabular}

Values correspond with one single analysis. For abbreviations, see Table 1 
discrepancy between the treated groups and the control grew as the nauplii grew older. Overall performance of the VC nauplii (control and treatments) was better than for the GSL sample (Table 2; Fig. 2a, b).

\section{Energy content}

The number of cysts per gram and the energy content of hydrated/dehydrated decapsulated cysts and instar I nauplii (J/g dry weight) were higher for VC than for GSL, but the individual cyst energy content was lower in VC cysts, which are smaller than GSL cysts (Table 3). Moreover, in both strains, the individual energy content was higher in the control than in the hydrated/dehydrated cysts, with a gradual decrease in energy content as the number of H/D cycles and the duration of the hydration period increased, illustrating that the cysts consume energy while being hydrated. The rate of energy loss during exposure to the various H/D treatments was similar for both strains (Table 3; Fig. 2a, b). In both strains, cysts lost more energy when being hydrated for $4 \mathrm{~h}$, than when being hydrated twice for $2 \mathrm{~h}$ (e.g., $8.9 \mathrm{vs}$. $3.7 \%$ for A2 and A11, respectively, VC cysts). In both strains, a double or a triple H/D cycle did not result in a two- or threefold decrease in individual energy content.

Fatty acid composition

A total of 28 fatty acids were recorded (Table 4). The saturated fatty acids (SFA) were dominated by 16:0 and 18:0 in the two strains. Among the monounsaturated fatty acids (MUFA), 18:1n-9 was the most abundant in the two strains with values in the range $19.2-27.5 \mathrm{mg} \mathrm{g}^{-1} \mathrm{DW}$; this fatty acid showed higher levels in the GSL control and A222 cysts and nauplii than in the corresponding VC samples. Of all HUFAs, 18:3n-3 dominated in the GSL samples (43.4-51.8 $\mathrm{mg} \mathrm{g}^{-1}$ DW in cysts and nauplii), whereas in VC 20:5n-3 was the most abundant HUFA $17.0-19.9 \mathrm{mg} \mathrm{g}^{-1}$ DW in cysts and nauplii.

Though variations were found among the individual fatty acids, in general total (n-3), total (n-6), and total fatty acids were higher in the nauplii than in the corresponding cyst samples. In addition, total fatty acid levels of the samples exposed to H/D cycles were slightly lower than in the control in both cysts and nauplii, but there was no effect of the $\mathrm{H} / \mathrm{D}$ cycles on the levels of highly unsaturated fatty acids, such as eicosapentaenoic acid (EPA, 20:5n-3), docosahexaenoic acid (DHA, 22:6n-3), arachidonic acid (ARA, 20:4n-6), or linolenic acid (18:3n-3), illustrating that net breakdown of HUFAs during the hydration/ dehydration process is limited (Table 4).

\section{Vitamin C content}

Considerably higher vitamin $\mathrm{C}$ values, expressed as ascorbic acid, were found in the control nauplii $\left(0.676\right.$ and $\left.0.803 \mathrm{mg} \mathrm{g}^{-1} \mathrm{DW}\right)$ than in the control cysts $(0.289$ and $0.367 \mathrm{mg} \mathrm{g}^{-1} \mathrm{DW}$ ), for VC and GSL, respectively. In both strains, three H/D cycles with 4-h hydration decreased the vitamin $\mathrm{C}$ content with 62-69\% in cysts and about $10 \%$ in nauplii (Table 4).

Correlations between quality parameters

Linear regression analysis between hatching percentage (on day 0, after 1 week, and 1 month of storage) on the one hand and individual energy content of cysts on the other 

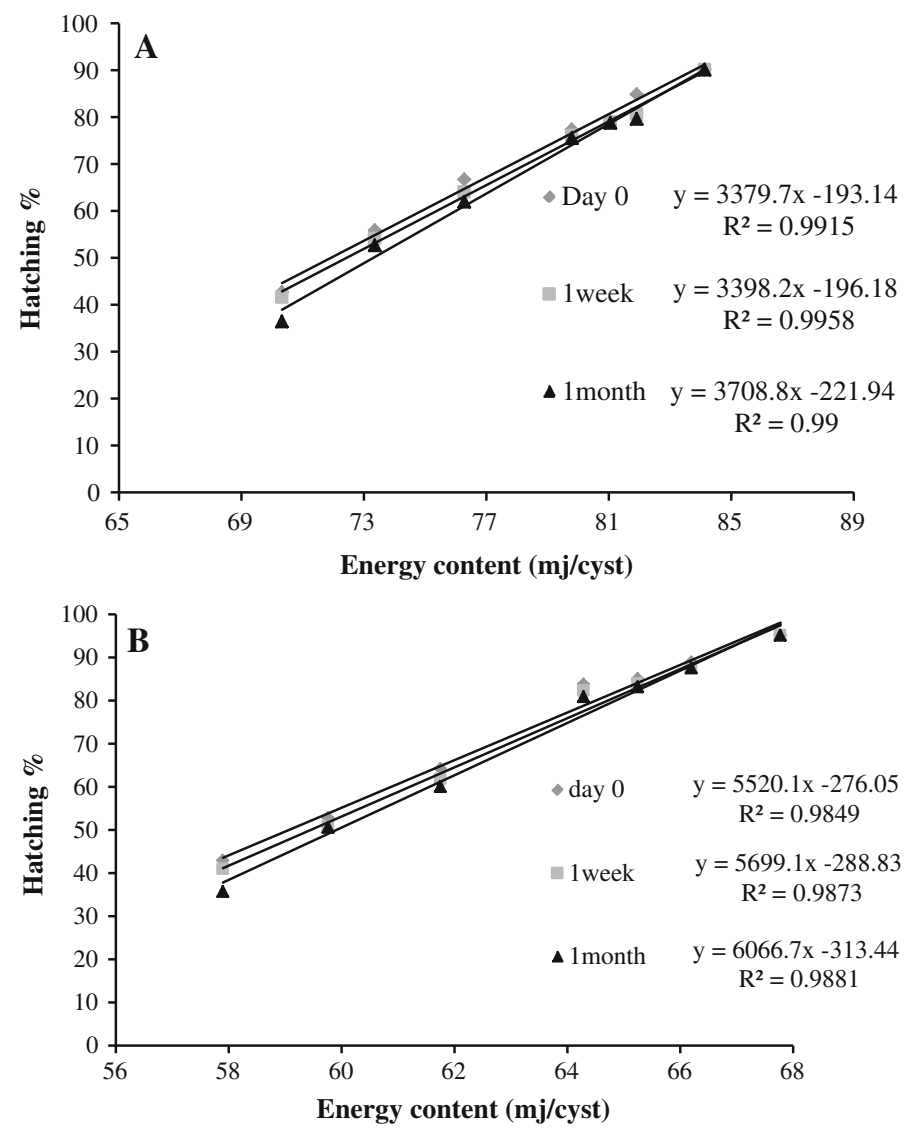

Fig. 3 a Linear regression between hatching percentage (on day 0, after 1 week, and 1 month of storage) and energy content $\left(\mathrm{mj} \mathrm{cyst}^{-1}\right)$ in GSL cysts exposed to various H/D cycles. b Linear regression between hatching percentage (on day 0 , after 1 week, and 1 month of storage) and energy content (mj cyst ${ }^{-1}$ ) in $\mathrm{VC}$ cysts exposed to various $\mathrm{H} / \mathrm{D}$ cycles

indicated a very strong positive correlation in both GSL and VC strains $\left(R^{2}>0.99\right.$ for GSL and $R^{2}>0.98$ for VC (Fig. 3a, b), A similar positive correlation was found between survival of the starved nauplii and the energy content (expressed in $\mathrm{J} \mathrm{g}^{-1}$ dry weight) of instar I nauplii $\left(R^{2}>0.95\right.$ for GSL and $R^{2}>0.92$ for VC (Fig. $4 \mathrm{a}, \mathrm{b}$ ). There were no significant differences $(P>0.05)$ between the slopes and between the intercepts of the regression lines in Fig. 3a, b, whereas in both Fig. 4a, b all slopes and intercepts of the four regression lines were significantly different $(P<0.05)$ from each other.

\section{Discussion}

The ability of Artemia to form cysts accounts in part for its convenience as a larval food source (Léger et al. 1986). Artemia cysts have a remarkable shelf life; the ease and simplicity of hatching make brine shrimp one of the most convenient, least labor-intensive live foods available for aquaculture. 

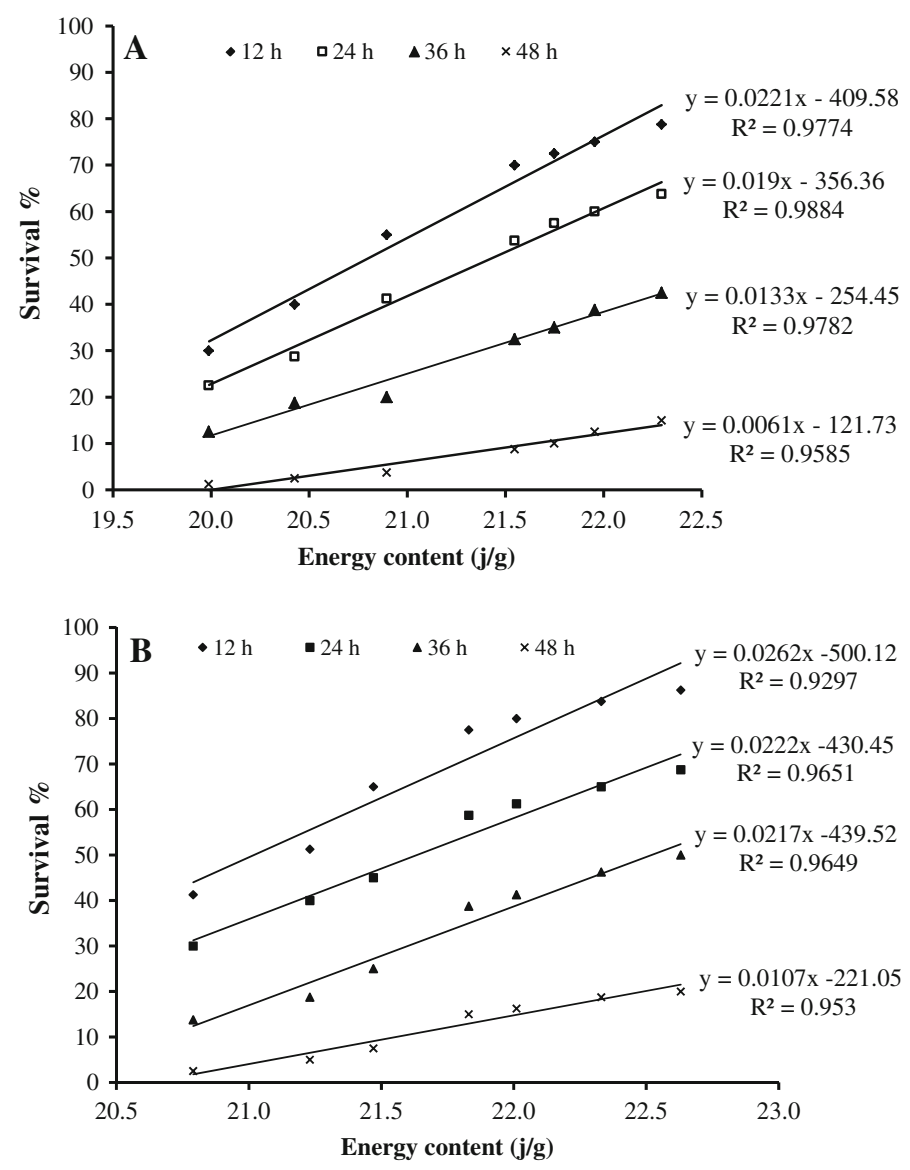

Fig. 4 a Linear regression between survival \% (after 12, 24, 36, and $48 \mathrm{~h}$ ) and energy content $\left(\mathrm{J} \mathrm{g}^{-1} \mathrm{DW}\right)$ of GSL instar I nauplii after exposure of the cysts to various H/D cycles. b Linear regression between survival \% (after 12, 24, 36, and $48 \mathrm{~h}$ ) and energy content $\left(\mathrm{J} \mathrm{g}^{-1} \mathrm{DW}\right)$ of VC instar I nauplii after exposure of the cysts to various $\mathrm{H} / \mathrm{D}$ cycles

This study aimed to gauge to what extent cyclic H/D exposure of cyst samples from two commercially important A. franciscana strains (Great Salt Lake, USA, and the San Francisco Bay-type Vinh Chau, Vietnam) resulted in quality loss as assessed by aquaculture-relevant parameters such as hatching, longevity, and nutritional quality of nauplii.

The untreated cyst samples used in our study were in quiescence, as illustrated by the high hatching percentage $(>90 \%)$. The hatching quality of the cysts was negatively affected when cysts were stored after exposure to a succession of H/D cycles, and this effect aggravated as the number of cycles increased from one to three, and as the hydration period, preceding dehydration, was lengthened from 2 to $4 \mathrm{~h}$, finally resulting in a loss of hatching in the range 50-60\% of the control value. The loss as a result of multiple H/D cycles was more marked when a hydration period of $4 \mathrm{~h}$ was used, as compared with hydration during $2 \mathrm{~h}$. The difference in water content of the VC and GSL control sample (34.8 vs. $4.5 \%$, respectively) did not affect these results: after incubation in seawater, cysts absorb water at a fast rate, reaching a maximal water content of $140 \%$ of their dry weight after $1.0-1.5 \mathrm{~h}$ at $28.0^{\circ} \mathrm{C}$, as described by (Lavens and Sorgeloos 1987). 
A similar effect was found for the axenically hatched nauplii with survival negatively affected by increasing H/D cycles, longer hydration incubation, and prolonged starvation over a 48-h observation period, as energy reserves were gradually depleted (Benijts et al. 1976). Analogously, the individual energy content, being maximal in the control cysts, gradually declined as the number of H/D cycles and the duration of the hydration period increased, corresponding with energy consumption during the repeated hydration process (Morris 1971; Vanhaecke and Sorgeloos 1982; Vanhaecke et al. 1983). In both strains, hydration for $4 \mathrm{~h}$ resulted to more than three times (3.5-3.8 times) the energy loss resulting from hydration for $2 \mathrm{~h}$, illustrating that as hydration continues, metabolism intensifies and energy consumption proceeds at a faster rate (Lavens and Sorgeloos 1987). On the other hand, doubling or tripling the H/D cycle did not result in an accordingly double or triple energy loss. This suggests that after the first cycle, a number of metabolic mechanisms have been initiated, which are not repeated during the following cycles. The similarity in energy consumption during the successive H/D cycles, observed in both strains, suggests that the underlying mechanisms are common within the species A. franciscana and possibly within the genus Artemia. Nevertheless, as energy content in the cysts dropped, cyst hatching and naupliar survival decreased faster in VC than in GSL, as reflected in the slope of the regression curves (Figs 3b, 4b), indicating that VC cysts are more sensitive to improper storage conditions than GSL, which may be linked to their smaller size (generally with a diameter of approximately $225 \mu \mathrm{m}$ for VC, as compared to about $250 \mu \mathrm{m}$ for GSL cysts (Vanhaecke and Sorgeloos 1980; Dhont and Sorgeloos 2002).

Comparative literature information on the fatty acid contents of cysts and the nauplii emerging from them is scarce (Garcia-Ortega et al. 1998; Dhont and Sorgeloos 2002), and no information is available on the fatty acid metabolism involved in the hatching process. Our FAME results of control decapsulated cysts and nauplii of the VC and GSL strains, and the differences in dominating fatty acids between both strains, are similar to the literature data published for those strains (Evjemo et al. 1997; Garcia-Ortega et al. 1998; Dhont and Sorgeloos 2002; Ando et al. 2002). The effect of hydration and subsequent dehydration on the fatty acid contents of cysts has not been the subject of systematic studies in the past; in our study, differences between the control and A222 samples were limited, which suggests that net fatty acid breakdown during the hydration/ dehydration process is limited. This is also illustrated by the similarity between the data of fatty acid contents reported in the literature by various authors for (GSL or VC) samples, which may have a widely diverging history of exposure to hydration and dehydration prior to analysis.

In general, fatty acid analysis showed that the two populations of Artemia from Vinh Chau and from Great Salt Lake are essentially different in fatty acid composition, especially in terms of EPA (20:5n-3) and linolenic acid (18:3n-3) contents. Variations in cyst fatty acid profile are generally linked to the characteristics of the phytoplankton population as food source for the maternal population (Navarro and Amat 1992, Navarro et al. 1992; Zhukova et al. 1998; Thinh et al. 1999, Torrentera and Dodson 2004), though also other environmental parameters, such as ambient temperature, and genetic factors may have an effect (Ruiz et al. 2007, 2008; Nguyen Thi Hong Van, unpublished results).

In order to meet the nutritional requirements of especially marine fish and shellfish larvae, enrichment of Artemia metanauplii is a standard procedure in many hatcheries when using the HUFA-deficient GSL strain. HUFA levels post-enrichment thus overwhelm the levels of the freshly hatched nauplius, or of the metanauplius having gone 
through some period of starvation. Enrichment is not applied for the VC strain, however, which contains relatively high levels of highly unsaturated fatty acids. Moreover, strict hatching procedures (e.g., harvesting of nauplii after a hatching incubation period of $24 \mathrm{~h}$ ) generally reduce the risk of starved (meta) nauplii being fed to (shell) fish larvae.

Vitamin $\mathrm{C}$ levels were conforming to the conversion of vitamin $\mathrm{C}$ from ascorbic sulfate into ascorbic acid during completion of the embryonic development into the nauplius stage (Dabrowski 1991; Golub and Finamore 1972; Nelis et al. 1994) and comparable to the range (162-428 $\left.\mu \mathrm{g} \mathrm{g}^{-1} \mathrm{DW}\right)$ reported by (Dabrowski 1991) for cysts. The variation in vitamin $\mathrm{C}$ contents found between cysts of different geographical origin (in the range 296-517 $\mu \mathrm{g} \mathrm{g}^{-1}$ DW expressed as ascorbic acid), its conversion into free ascorbic acid during the hatching process, and the role of ascorbic sulfate as storage form has been studied in detail (Mead and Finnamore 1969; Merchie et al. 1995). The nutritional quality of the A222 cysts and nauplii was lower than in the control, as shown by reduced fatty acid and vitamin $\mathrm{C}$ levels. In the case of vitamin $\mathrm{C}$, this loss amounted in both strains up to $62-69 \%$ for A222 cysts as compared to the control, whereas fatty acid losses were generally in the order of few percentages.

Knowledge of hatching characteristics in Artemia samples is important due to the reported variability among batches and strains. The nutritional quality in Artemia varies considerably as well, in relationship with its geographical origin (Léger et al. 1986). (Vanhaecke and Sorgeloos 1982) reported that the poor hatchability of commercial batches of Artemia cysts can be linked to improper processing of the cysts after collection in nature, and that long-term storage of such material may result in a further substantial decrease in hatching success. In natural conditions, cysts may be exposed to H/D cycles, as they are floating driven by wind and currents, and may temporally or definitively accumulate on the shore where they undergo the fluctuations of atmospheric conditions. Harvesting of good-quality cyst product requires collection of recently produced cyst batches from the open water shortly followed by adequate processing, but these conditions are seldom fulfilled, especially when harvesting natural production in inland lakes, when site accessibility is limited, timing of harvesting is irregular, transport and storage is an issue, and/or overall expertise is lacking. In Artemia pond production, such as in the Mekong Delta, Vietnam, frequent harvesting (up to 2-3 times a day) followed by adequate processing is currently done, which contributes to the good quality of the resulting cyst product (Anh et al. 2009).

Our results confirm that cyst metabolism, as initiated after hydration, is to a certain degree reversible and that cysts can be converted from a hydrated, metabolically active mass of cells into a dehydrated, ametabolic state (and vice versa). They also show that repeated H/D cycles not only result in a decreased hatching output, but also in an inferior quality of those nauplii hatching, as quantified in our study by naupliar longevity, energy, FAME, and vitamin C content. These observations are of fundamental importance in understanding the cysts quality and they have significant potential for application in aquaculture.

Acknowledgments The authors are grateful to the Ministry of Higher Education of the Libyan Government who supported this study through a doctoral grant to the first author. The technical assistance of Geert Vandewiele (Laboratory of Aquaculture \& Artemia Reference Center) for the FAME and vitamin C analyses is greatly appreciated. We are also grateful to Dan Curvers from the Particle and Interfacial Technology Group, Faculty of Bioscience Engineering, Ghent University, for the energy content determination. Kristof De Beuf (Ghent University FIRE) is acknowledged for providing assistance in statistical processing of data. 


\section{References}

Abatzopoulos THJ, Beardmore JA, Clegg JS, Sorgeloos P (2002) Artemia: basic and applied biology. Kluwer, Dordrecht

Ando Y, Oomi Y, Narukawa K (2002) Regiospecific distribution of fatty acids in triacylglycerols of Artemia franciscana nauplii enriched with fatty acid ethyl esters. Comp Biochem Phys B 133:191-199

Anh NTN, Hoa NV, Van Stappen G, Sorgeloos P (2009) Effect of different supplemental feeds on proximate composition and Artemia biomass production in salt ponds. Aquaculture 286:217-225

Baruah K, Ranjan J, Sorgeloos P, Bossier P (2010) Efficacy of heterologous and homologous heat shock protein $70 \mathrm{~s}$ as protective agents to Artemia franciscana challenged with vibrio campbellii. Fish Shellfish Immun 29:733-739

Benijts F, Van Voorden E, Sorgeloos P (1976) Changes in the biochemical composition of the early larval stages of the brine shrimp, Artemia salina L. In: Persoone G, Jaspers E (eds) Proceedings of 10th European symposium Mar Biol 1. Universa Press, Weteren pp 1-9

Bruggeman E, Sorgeloos P, Vanhaecke P (1980) Improvements in the decapsulation technique of Artemia cysts. In: The brine shrimp Artemia: Persoone G, Sorgeloos P, Roels O, Jaspers E (eds) Ecology, culturing, use in aquaculture, vol 3, Universa Press, Wetteren pp 261-269

Clegg JS (1997) Embryos of Artemia franciscana survive four years of continuous anoxia: the case for complete metabolic rate depression. J Exp Biol 200:467-475

Dabrowski K (1991) Some aspects of ascorbate metabolism in developing embryos of the brine shrimp. J Fish Aquat Sci 48:1-3

Dhont J, Sorgeloos P (2002) Applications of Artemia. In: Abatzopoulos TJ, Beardmore JA, Clegg JS, Sorgeloos P (eds) Artemia basic and applied biology. Kluwer, Dordrecht, pp 251-277

Drinkwater LE, Clegg JS (1991) Experimental biology of cyst diapause. In: Sorgeloos P, Trotman CNA, Browne RA (eds) Artemia biology. CRC Press, Boca Raton, pp 93-117

Drinkwater LE, Crowe JH (1987) Regulation of embryonic diapause in Artemia: environmental and physiological signals. J Exp Zool 241:297-307

Evjemo JO, Coutteau P, Olsen Y, Sorgeloos P (1997) The stability of docosahexaenoic acid in two Artemia species following enrichment and subsequent starvation. Aquaculture 155:135-148

Garcia-Ortega A, Verreth JAJ, Coutteau P, Segner H, Huisman EA, Sorgeloos P (1998) Biochemical and enzymatic characterization of decapsulated cysts and nauplii of the brine shrimp Artemia at different developmental stages. Aquaculture 161:501-514

Golub AL, Finamore FJ (1972) Ascorbic acid sulphate metabolism in the brine shrimp. Fed Proc 31:706

Kellogg VL (1906) A new Artemia its life conditions. Science 24:594-596

Lavens P, Sorgeloos P (1987) The cryptobiotic state of Artemia cysts and its diapause deactivation and hatching. A review. In: Sorgeloos P, Bengtson DA, Decleir W, Jaspers E (eds) Artemia research and its applications: ecology, culturing, use in aquaculture, vol 3. Universa Press, Wetteren, pp 27-63

Lavens P, Sorgeloos P (1996) Manual on the production and use of live food for aquaculture. FAO Fisheries Technical Paper No. 361

Lavens P, Tackaert W, Sorgeloos P (1986) International study on Artemia. XII. Influence of culture conditions and specific diapause deactivation methods on the hatchability of Artemia cysts produced in a standard culture system. Mar Ecol Prog Ser 31:197-203

Léger P, Bengtson DA, Simpson KL, Sorgeloos P (1986) The use and nutritional value of Artemia as a food source. Oceanogr Mar Biol 24:521-623

Lepage G, Roy CC (1984) Improved recovery of fatty acid through direct transesterification without prior extraction or purification. J Lipid Res 25:1391-1396

MacRae TH (2003) Molecular chaperones, stress resistance and development in Artemia franciscana. Semin Cell Dev Biol 14:251-258

MacRae TH (2005) Diapause, diverse states of developmental and metabolic arrest. J Biol Res 3:3-14

Marques A, François J, Dhont J, Bossier P, Sorgeloos P (2004) Influence of yeast quality on performance of gnotobiotically-grown Artemia. J Exp Mar Biol Ecol 310:247-264

Mead CG, Finnamore FJ (1969) The occurrence of ascorbic acid sulfate in the brine shrimp, Artemia salina. Biochemistry 8:2652-2655

Merchie G, Lavens P, Dhert P (1995) Variation of ascorbic acid content in different live food organisms. Aquaculture 134:325-337

Morris JE (1971) Hydration, its reversibility and the beginning of development in the brine shrimp, Artemia salina. Comp Biochem Physiol 39A:843-857

Nambu Z, Tanaka S, Nambu F, Nakano M (2008) Influence of temperature and darkness on embryonic diapause termination in dormant Artemia cysts that have never been desiccated. J Exp Zool 309:17-24 
Navarro JC, Amat F (1992) Effect of algal diets on the fatty acid composition of the brine shrimp, Artemia sp. cysts. Aquaculture 101:223-227

Navarro JC, Amat F, Sargent J (1992) Fatty acid composition of coastal and inland Artemia sp. populations from Spain. Aquaculture 102:219-230

Nelis HJ, Merchie G, Lavens P, Sorgeloos P, De Leenheer AP (1994) Solid phase extraction of ascorbic acid-2-sulfate from cysts of the brine shrimp Artemia franciscana. Anal Chem 66:1330-1333

Persoone G, Sorgeloos P (1980) General aspects of the ecology and biogeography of Artemia. In: The brine shrimp Artemia: Persoone G, Sorgeloos P, Roels O, Jaspers E (eds) Ecology, culturing, use in aquaculture, vol 3. Universa Press, Wetteren, pp 3-24

Ruiz O, Medina GR, Cohen RG, Amat F, Navarro JC (2007) Diversity of the fatty acid composition of Artemia spp. cysts from Argentinean populations. Mar Ecol Prog Ser 335:155-165

Ruiz O, Amat F, Navaro JC (2008) A comparative study of the fatty acid profile of Artemia franciscana and A. persimilis cultured at mesocosm scale. J Exp Mar Biol Ecol 354:9-16

Sorgeloos P (1980) The use of brine shrimp Artemia in Aquaculture. In: Persoone G, Sorgeloos P, Roels O, Jaspers E (eds) The brine shrimp Artemia: Ecology, culturing, use in aquaculture, vol 3. Universa Press, Wetteren, pp 25-54

Sorgeloos P, Baeza-Mesa M, Benijts F, Persoone G (1976) Research on the culturing of the brine shrimp Artemia salina L. In: Mariculture: Persoone G, Jaspers E (Eds). Proceeidngs of 10th European symposium. Mar. Biol 1 at the State University of Ghent, Belgium. Universa Press, Wetteren, pp 473-495

Thinh LV, Renaud SM, Parry DL (1999) Evaluation of recently isolated Australian tropical microalgae for the enrichment of the dietary value of brine shrimp, Artemia nauplii. Aquaculture 170:161-173

Torrentera L, Dodson SI (2004) Ecology of the brine shrimp Artemia in the Yucatan, Mexico, salterns. J Plankton Res 26:617-624

Triantaphyllids GV, Abatzopoulos TJ, Sorgeloos P (1998) Review of the biogeography of the genus Artemia (Crustacea, Anostraca). J Biogeogr 25:213-226

Van Der Linden A, Blust R, Van Laere AJ, De Cleir W (1988) Light-induced release of Artemia dried embryos from diapause: analysis of metabolic status. J Exp Zool 247:131-138

Vanhaecke P, Sorgeloos P (1980) International Study on Artemia. IV. The biometrics of Artemia strains from different geographical origin. In: The brine shrimp Artemia: Persoone G, Sorgeloos P, Roels O, Jaspers E (eds) Ecology, culturing, use in aquaculture, vol 3, Universa Press, Wetteren, pp 393-405

Vanhaecke P, Sorgeloos P (1982) International Study on Artemia. XVIII. The hatching rate of Artemia cysts: a comparative study. Aquacult Eng 1:263-273

Vanhaecke P, Lavens P, Sorgeloos P (1983) International Study on Artemia. XVII. Energy consumption in cysts and early larval stages of various geographical strains of Artemia. Ann Soc R Zool Belg 113:155-164

Zhukova NV, Imbs AB, Lia Fa Y (1998) Diet-induced changes in lipid and fatty acid composition of Artemia salina. Comp Biochem Physiol 120B:499-506 